\title{
DERMATOPATIAS EM CÃES: REVISÃO DE 257 CASOS
}

\author{
Mauro José Lahm Cardoso ${ }^{1}$, Luiz Henrique Araújo Machado², Maíra Melussi ${ }^{3}$, Thaís \\ Pitelli Zamarian', Cássia Maria Carnielli ${ }^{3}$, José Carlos Melo Ferreira Júnior ${ }^{3}$ \\ 1 UENP-CLM \\ 2 FMVZ-UNESP \\ 3 Autônomo
}

Endereço para correspondência: Mauro José Lahm Cardoso: maurolahm@uenp.edu.br

\begin{abstract}
RESUMO: O presente estudo teve como objetivo coletar dados retrospectivos das dermatopatias em cães atendidos no Hospital Veterinário (HV) da Universidade Estadual do Norte do Paraná (UENP), Bandeirantes-PR. Os casos dermatológicos atendidos corresponderam a $31,38 \%$ de todas as consultas realizadas em cães e as dermatoses mais observadas neste estudo foram, em ordem decrescente, as bacterianas, parasitárias, fúngicas, imunológicas, distúrbios de ceratinização, doenças cutâneas diversas e dermatopatias psicogênicas. As doenças de maior ocorrência foram, em ordem decrescente, a foliculite superficial, demodicidose, dermatofitose, otite bacteriana, foliculite profunda, disqueratinização seca, dermatite alérgica a picada de pulgas, otite fúngica, escabiose, impetigo, malasseziose, otite parasitária, pododermatite e dermatite atópica. Os resultados mostraram que a dermatologia na medicina veterinária de cães, sendo que o diagnóstico e o manejo dessas enfermidades devem ser considerados de extrema importância aos clínicos de pequenos animais.
\end{abstract}

Palavras-chave: bacteriana; fúngica; imunológica; parasitária; dermatopatias; cães.

\section{SKIN DISEASES IN DOGS: A REVIEW OF 257 CASES}

\begin{abstract}
The purpose of this study was to collect data on skin diseases in dogs evaluated at the Veterinary Hospital of the Northern Parana State University (UENP), in Bandeirantes, Parana, Brazil. Dermatological conditions amounted to $31.38 \%$ of all consultations in dogs, and the most common skin conditions observed were, from the most to the least common: bacterial, parasitic, fungal, immune, and keratinization disorders; general skin diseases and psychogenic conditions. The highest scoring diseases, in number of occurrences were, in descending order: Superficial folliculitis, demodicidosis, dermatophytosis, bacterial otitis, deep folliculitis, dry dekeratinization, allergic dermatitis caused by flea bites, fungal ear infections, scabies, impetigo, malassezia dermatitis, parasitical otitis, pad dermatitis, and atopic dermatitis.
\end{abstract}

Key Words: bacterial; fungal; immune; parasitic; skin diseases; dogs. 


\section{INTRODUÇÃO}

Os casos dermatológicos apresentam grande prevalência em pequenos animais, sendo a razão mais comum para serem levados ao médico veterinário (SCOTT; MILLER; GRIFFIN, 2001; HIIL et al., 2006). Estima-se que entre 20 e $75 \%$ de todos os animais examinados na prática clínica veterinária apresentem enfermidades do sistema tegumentar como queixa principal ou como doença secundária (IHRKE, 1996; SCOTT; MILLER; GRIFFIN, 2001). Que o primeiro estudo realizado na década de 70 demonstraram que, na Inglaterra, 20\% dos cães e $15 \%$ dos gatos apresentavam enfermidades de pele e ouvido (EVANS; LANE; HENDY, 1974), semelhante ao encontrado posteriormente no Canadá, onde 0 índice foi de $18,8 \%$ dos cães e $15,2 \%$ dos gatos (SCOTT; PARADIS, 1990). Em 2001, nos Estados Unidos, esta incidência chegou a 25\% (SCOTT; MILLER; GRIFFIN, 2001).

Nos EUA, uma pesquisa realizada em 2001, incluindo 17 hospitais veterinários ligados a instituições de ensino, notou-se que as doenças dermatológicas mais freqüentes foram, em ordem decrescente, a dermatite alérgica à picada de ectoparasita (DAPE), neoplasias cutâneas, piodermite bacteriana, seborréia, dermatites alérgicas, demodicidose, escabiose, dermatoses imunomediadas, dermatoses endócrinas e dermatite acral por lambedura (SCOTT; MILLER; GRIFFIN, 2001).

O objetivo deste trabalho foi fornecer dados sobre a ocorrência das dermatopatias em cães atendidos no Hospital Veterinário (HV) da Universidade Estadual do Norte do Paraná (UENP), campus Luiz Meneghel.

\section{MATERIAL E MÉTODOS}

Foram avaliados 819 prontuários de cães arquivados no Serviço de Arquivo do HV-UENP -Bandeirantes - PR. durante o período de fevereiro de 2003 a dezembro de 2006, dos quais 257 apresentavam alguma doença de pele como diagnóstico primário ou secundário.

Nestes prontuários constam a anamnese, exame físico e os resultados dos exames complementares. Em todos os 257 cães realizaram-se os exames necessários para o diagnóstico da dermatopatia e o diagnóstico foi estabelecido pelos resultados laboratoriais ou por exclusão. Os métodos complementares utilizados foram: exame parasitológico por raspado cutâneo, exame otológico, cultura e antibiograma de secreções cutâneas e de conduto auditivo, cultura fúngica, exame direto de pêlos, exame citológico e histopatologia de pele. Os parâmetros analisados foram: sexo, idade, raça e doença diagnosticada. $O$ estudo da distribuição das prevalências foi realizado considerando o teste do Qui-quadrado para uma amostra e o nível de $5 \%$ de significância (STREINER; NORMAN, 1994). Associado ao resultado do teste estatístico indicou-se o nível descritivo do teste $(p)$. 


\section{RESULTADOS E DISCUSSÃO}

Dos 819 prontuários avaliados, 257 apresentavam alguma dermatopatia como diagnóstico primário ou secundário, ou seja, os casos dermatológicos representaram 31,38\% dos animais atendidos. Estes dados são superiores aos já obtidos anteriormente na literatura, cujas afecções dermatológicas representavam 15 a 25\% (EVANS; LANE; HENDY, 1974; HIIL et al., 2006; SCOTT; MILLER; GRIFFIN, 2001; SCOTT; PARADIS, 1990). Esta alta incidência pode ser explicada devido ao crescimento desta especialidade dentro da medicina veterinária e consequentemente à dedicação e capacitação dos profissionais. $O$ excesso de cuidado (número de banhos) e o uso de produtos de higiene e beleza também são fatores contribuintes ao desenvolvimento das dermatopatias.

Os resultados obtidos estão apresentados na Tabela 01.
Tabela 01 - Distribuição das doenças dermatológicas diagnosticadas, bem como idade média (meses) e sexo, em 257 cães atendidos no HV-FALM-UENP, Bandeirantes-PR.

\begin{tabular}{|c|c|c|c|c|c|}
\hline \multirow[b]{2}{*}{ Doença Dermatológica } & \multicolumn{2}{|c|}{ Freqüência } & \multirow[b]{2}{*}{$\begin{array}{l}\text { Idade Média } \\
\text { (Meses) }\end{array}$} & \multicolumn{2}{|c|}{ Sexo } \\
\hline & $\begin{array}{l}\text { Absolut } \\
a(n)\end{array}$ & $\begin{array}{l}\text { Relativa } \\
(\%)\end{array}$ & & $\begin{array}{l}\text { Mac } \\
\text { ho }\end{array}$ & $\begin{array}{l}\text { Fêm } \\
\text { ea }\end{array}$ \\
\hline \multicolumn{6}{|l|}{ Dermatopatias bacterianas } \\
\hline Foliculite superficial & $40^{\mathrm{a}}$ & 15,56 & 41 & 20 & 20 \\
\hline Foliculite profunda & $18^{\mathrm{b}}$ & 7 & 39 & 8 & 10 \\
\hline Impetigo & $9^{\mathrm{bc}}$ & 3,5 & 14 & 2 & 7 \\
\hline Pododermatite & $7^{\mathrm{C}}$ & 2,72 & 41 & 5 & 2 \\
\hline $\begin{array}{l}\text { Foliculite, furunculose, } \\
\text { celulite }\end{array}$ & $4^{\mathrm{C}}$ & 1,56 & 56 & $4^{\mathrm{a}}$ & $0^{\mathrm{b}}$ \\
\hline Total & 78 & 30,35 & & 39 & 39 \\
\hline \multicolumn{6}{|l|}{ Dermatopatias parasitárias } \\
\hline Demodicidose & $31^{a}$ & 12,06 & 29 & $9^{a}$ & $22^{b}$ \\
\hline Escabiose & $9^{b}$ & 3,5 & 30 & 5 & 4 \\
\hline Total & 40 & 15,56 & & 14 & 26 \\
\hline
\end{tabular}

Dermatopatias fúngicas

\begin{tabular}{llllll} 
Dermatofitose & $29^{\mathrm{a}}$ & 11,28 & 21 & 13 & 16 \\
Malasseziose & $9^{\mathrm{b}}$ & 3,5 & 88 & 5 & 4 \\
\hline Total & 38 & 14,79 & & 18 & 20 \\
\hline
\end{tabular}

\begin{tabular}{|c|c|c|c|c|c|}
\hline \multicolumn{6}{|l|}{ Desordens imunológicas } \\
\hline $\begin{array}{l}\text { Dermatite alérgica a picada } \\
\text { de ectoparasita }\end{array}$ & $11^{\mathrm{a}}$ & 4,29 & 45 & 4 & 9 \\
\hline Dermatite atópica & $10^{\mathrm{a}}$ & 3,88 & 38 & 1 & 4 \\
\hline Lúpus eritematoso discóide & $2^{\mathrm{b}}$ & 0,77 & 96 & 2 & 2 \\
\hline Hipersensibilidade Alimentar & $4^{\mathrm{b}}$ & 1,56 & 47 & 2 & 0 \\
\hline Total & 27 & 10,52 & & 9 & 18 \\
\hline \multicolumn{6}{|l|}{ Desordens de ceratinização } \\
\hline Seborréia seca & $14^{\mathrm{a}}$ & 5,45 & 48 & 9 & 5 \\
\hline Seborréia oleosa & $3^{\mathrm{b}}$ & 1,17 & 66 & 2 & 1 \\
\hline Dermatite seborréica & $2^{\mathrm{b}}$ & 0,77 & 36 & 2 & 0 \\
\hline Total & 19 & 7,39 & & 13 & 6 \\
\hline \multicolumn{6}{|l|}{ Doenças cutâneas diversas } \\
\hline Foliculite de calo de apoio & $4^{\mathrm{a}}$ & 1,56 & 66 & 2 & 2 \\
\hline Dermatite solar & $2^{\mathrm{a}}$ & 0,77 & 36 & 2 & 0 \\
\hline Saculite & $1^{\mathrm{a}}$ & 0,39 & 132 & 0 & 1 \\
\hline Total & 7 & 2,72 & & 4 & 3 \\
\hline \multicolumn{6}{|l|}{ Dermatoses psicogênicas } \\
\hline $\begin{array}{lll}\begin{array}{l}\text { Dermatite } \\
\text { lambedura }\end{array} & \text { acral } & \text { por } \\
\end{array}$ & 3 & 1,17 & 60 & 1 & 2 \\
\hline Total & 3 & 1,17 & 60 & 1 & 2 \\
\hline \multicolumn{6}{|l|}{ Otite Externa } \\
\hline Otite bacteriana & $27^{\mathrm{a}}$ & 10,51 & 83 & 9 & 18 \\
\hline Otite fúngica & $11^{\mathrm{b}}$ & 4,28 & 50 & 4 & 3 \\
\hline $\begin{array}{l}\text { Otite mista (bacteriana, } \\
\text { fúngica) }\end{array}$ & $7^{\mathrm{b}}$ & 2,72 & 15 & 4 & 7 \\
\hline & 45 & 17,51 & & 17 & 28 \\
\hline
\end{tabular}


Valores alinhados seguidos de letras iguais não diferem $(\mathrm{P}>0,05)$.

Os diagnósticos encontrados, de acordo com a etiologia, foram: dermatopatias bacterianas $(30,35 \%)$, parasitárias (15,56\%), fúngicas $(14,79 \%)$, desordens imunológicas $(10,51 \%)$, desordens de ceratinização $(7,39 \%)$, dermatoses psicogênicas $(1,17 \%)$, otite externa $(17,51 \%)$, além de outras dematopatias $(2,72 \%)$.

As afecções dermatológicas mais freqüentes foram foliculite superficial $(15,56 \%)$, demodicidose (12,06\%), dermatofitose $(11,28 \%)$, otite bacteriana $(10,51 \%)$, seborréia seca $(5,45 \%)$ e DAPE (5,06\%), semelhante ao encontrado por Meneses (2000) e Hiil et al. (2006). Neste levantamento não foi observado nenhum caso de neoplasia cutânea, apesar de ser comum em cães.

As dematopatias bacterianas foram às afecções encontradas com maior frequência, semelhante ao estudo de 1990 onde a foliculite e furunculose bacteriana foram diagnosticadas em $25,3 \%$ dos casos (SCOTT; PARADIS, 1990). Diferindo do encontrado mais recentemente por Hiil et al. (2006) onde estas representaram apenas 11,09\%. Dos 58 casos de foliculite superficial e profunda cerca de $80 \%$ dos casos (46) eram secundárias e 12 primárias. A demodicidose, escabiose e as alergopatias foram as principais causas de foliculite secundária.

A foliculite superficial é uma infecção bacteriana freqüente que acomete superficialmente o tegumento (EDWARDS et al., 1997; HOLM; REST; SEEWALD, 2004; IHRKE, 199) e foi encontrada nesta revisão em $15 \%$ dos casos de dermatopatias bacterianas, apresentando diferença estatística com as demais infecções bacterianas de pele. As outras formas de piodermite não apresentaram diferença significativa entre si. As raças mais acometidas pelas dermatopatias bacterianas foram American pit bull com 23,08\%, Cocker spaniel inglês com $11,54 \%$ e os cães sem raça definida (SRD) com 19,23\%, contudo, não foi observada predisposição racial.

A demodicidose é uma doença com alta incidência na dermatologia veterinária (GHUBASH, 2006; MUELLER, 2004; SCOTT; MILLER; GRIFFIN, 2001), o que pôde ser confirmado neste estudo (12,6\%). No Brasil, a demodicidose representa $40 \%$ (DELAYTE et al., 2006) à 48,28\% (BELLATO et al., 2003) das causas de dermatopatias parasitárias, percentuais inferiores ao $77,5 \%$ observado neste estudo. Os índices nacionais são diferentes dos encontrados por pesquisadores britânicos, pois estes observaram a demodicidose somente em $0,89 \%$ dentre os casos de dermatopatias (Hill et al., 2006), o que pode ser justificado pela provável esterilização de animais portadores da doença clínica. Este fato não ocorre rotineiramente no Brasil, pois muitos proprietários não seguem a recomendação veterinária e continuam realizando cruzamentos indesejáveis.

A freqüência da demodicidose é maior em cães de raça e seus cruzamentos (SCOTT; MILLER; GRIFFIN, 2001; ZIVICNJAK, 2005), especialmente aqueles de pêlo curto, como basset hound, beagle, boston terrier, boxer, buldogue, chihuahua, dachshund, dálmata, doberman pinscher, pointer inglês e pug. Entretanto, a doença ocorre regularmente em animais de pelagem mais longa, como pastores alemão e inglês, collie, afgan hound, cocker spaniels e shar pei (SCOTT; MILLER; GRIFFIN, 2001). Os cães mais acometidos foram os sem raça definida (SRD) com $41,94 \%$ e os da raça American pit bull com $16,13 \%$. Os cães SRD diferiram significativamente das demais raças, entretanto, a ocorrência da demodicidose em cães da raça american pit bull não apresentou 
diferença significativa com as demais raças. A razão pela qual a ocorrência foi maior em cães SRD e american pit bull se deve ao fato de serem cães comuns na área de abrangência desta pesquisa. Os resultados não possibilitam afirmar que a raça American pit bull como predisposta.

A escabiose (22,5\%) teve uma incidência menor que a demodicidose $(77,5 \%)$, porém, apresenta alta prevalência quando comparada com o índice de 1,07\%, encontrado por HILL et al (2006) o que pode ser decorrente do livre acesso à rua que os cães estudados apresentavam. Não foram observadas diferenças estatísticas quanto à raça ou sexo, concordando com CURTIS (2004).

Os dados sobre a freqüência da dermatofitose em cães são bastante conflitantes. Enquanto alguns autores relatam a freqüência variando de $5 \%$ a $20 \%$, outros colocam como uma enfermidade cutânea de baixa incidência variando entre $0,26 \%$ a 3,6\% (BALDA et al, 2004; LEWIS; FOIL; HOSGOOD, 1991; SCOTT; MILLER; GRIFFIN, 2001). A dermatofitose foi uma das doenças mais freqüentes, juntamente com a foliculite superficial, demodicidose e a otite bacteriana. Este fato provavelmente se deve à diferença climática, visto que Bandeirantes possui um clima quente e seco com temperaturas médias superiores à $25^{\circ} \mathrm{C}$ e a prevalência da doença tende a ser mais comum em clima tropical e subtropical (MORIELLO; DEBOER, 1995). Contudo, isto não é consensual na literatura (LARSSON; LUCAS; GERMANO, 1997; LEWIS; FOIL; HOSGOOD, 1991).

Com relação à faixa etária, a média de idade foi de 22 meses nos cães com dermatofitose, resultado semelhante ao obtido por diversos autores (SCOTT; PARADIS, 1990; SPARKES et al, 1993; TORRES; MOREIRA, 1994; BALDA et al, 2004).
Animais de qualquer idade, sexo ou raça são susceptíveis à infecção, embora a doença apresente tendência a ser mais comum em animais jovens, debilitados e velhos (MORIELLO, 2004). É possível que esta maior susceptibilidade dos animais jovens em adquirir a infecção esteja vinculada à maturidade do sistema imunológico (BALDA et al, 2004). Não verificou-se predisposição sexual, achado esse, já descrito na bibliografia desde a década de 90 (BALDA et al, 2004; LARSSON; LUCAS; GERMANO, 1997; TORRES; MOREIRA, 1994).

Os cães da raça American pit bull representaram $37,9 \%$ dos casos de dermatofitose, diferindo de outros estudos anteriores (BALDA et al, 2004; SPARKES et al, 1993). Enquanto, os cães sem raça definida e os da raça teckel representaram $27,59 \%$ e $13,78 \%$ dos casos, respectivamente. Não foi observada diferença estatística entre o American pit bull, teckel e sem raça definida. Contudo, estas raças apresentaram diferença com as demais raças com o diagnóstico de Dermatofitose. Balda et al. (2004) e Sparkes et al. (1991) descrevem a raça Yorkshire como a mais acometida. Ressalta-se que poucos cães desta raça foram atendidos com dermatopatia ou no Hospital Veterinário.

O Microsporum canis e o Microsporum gypseum foram responsáveis por todos os casos de dermatofitose nesse estudo, representando, respectivamente $62 \%$ e $38 \%$ dos casos. É estimado que o Microsporum canis seja responsável por cerca de 50 a $70 \%$ das dermatofitoses em cães (MACIEL, 2005) ou mais (BALDA et al, 2004), enquanto que o Microsporum gypseum e o Trichophyton mentagrophytes, respectivamente, sejam responsáveis por $10 \%$ e $20 \%$ da dermatofitose em cães (BALDA et al, 2004; ROCHETTE; ENGELEN.; BOSSCHE, 2003). 


\section{As otites bacterianas}

representaram $17,51 \%$ dos casos dermatológicos atendidos, semelhante ao sugerido por Leite (2000) e Hiil et al. (2006) em que as otites representavam 8 a $15 \%$ e $17,6 \%$ dos casos atendidos na prática clínica veterinária, respectivamente. A ocorrência elevada de otite é multifatorial incluindo fatores raciais, outras doenças de peles como as alergopatias e doenças de queratinização, erros de manejo como arrancamento de pêlos e execesso de banhos.

Neste estudo, as otites ocorreram mais nas raças poodle $(24,44 \%)$, Ihasa apso $(15,55 \%)$ e cocker spaniel inglês $(13,33 \%)$, semelhantes ao descrito por outros autores (LEITE, 2000; NOBRE et al, 2001; OLIVEIRA et al, 2005). Os cães sem raça definida representaram $15,55 \%$ dos casos de otites. A alta incidência em cães da raça lhasa apso pode ser explicada pela predisposição às dermatopatias alérgicas $\mathrm{e}$ consequentemente à otite externa (SCOTT; MILLER; GRIFFIN, 2001). Enquanto nos cães da raça cocker spaniel inglês o fator racial e o complexo seborreico nãso importantes fatores desencadeantes e perpetuantes.

Dentre as dermatopatias alérgicas a Dermatite Atópica e a DAPE foram as mais freqüentes. $O$ poder aquisitivo dos proprietários e menor cuidado com os cães é uma das hipóteses para a maior ocorrência de DAPE. A ocorrência da DAPE $(4,29 \%)$ e da Dermatite Atópica (3,88\%) foram semelhantes ao descrito HIIL et al. (2006) que obteve 4,8\% em ambas doenças. Porém, a ocorrência descrita da dermatite atópica é ampla variando 3 a $15 \%$ da população canina, embora a real prevalência e incidência não sejam conhecidas (HILLIER; GRIFFIN, 2001; HILLIER, 2002; NASCENTE et al, 2006; JAEGER, et al., 2010).

A DAPE é uma desordem comum em cães, representando $50 \%$ das dermatoses alérgicas e muitas vezes coexistindo com outras enfermidades alérgicas como a dermatite atópica (VON RUEDORFFER et al, 2003), concordando com o resultado obtido nesta revisão, onde a DAPE ocorreu em $40,74 \%$ dos cães com doença cutânea alérgica. Essa dermatopatia tem aspecto freqüentemente sazonal, no entanto, em climas subtropical e tropical, há relatos de prevalência não sazonal (SCOTT; MILLER; GRIFFIN, 2001), como nos animais deste estudo.

Como a dermatite atópica representa uma genodermatose, a maior ocorrência da doença tem sido observada em cães de raça pura (DETHIOUX, 2006; FARIAS 2007; SCOTT; MILLER; GRIFFIN, 2001), fato confirmado neste estudo onde os cães da raça Ihasa apso representaram $40 \%$ dos casos de atopia. A predileção racial é bem relatada na literatura, porém as variações regionais existentes podem mudar essa predileção ao longo do tempo. As raças citadas como mais acometidas na literatura são: Cain Terriers, West Highland White Terriers, Terriers Escoceses, Lhasa Apsos, Shih Tzus, Fox Terriers de pêlo duro, Dálmatas, Pugs, Setters Irlandeses, Boston Terriers, Golden Retrievers, Boxers, Setters Ingleses, Labrador Retrievers, Schnauzer miniatura, Tervuren Belgas e Beaucerons. (JAEGER, et al., 2010).

Alguns autores relatam uma maior incidência de dermatite atópica em fêmeas, embora a predisposição sexual não tenha sido comprovada (MILLER \& KIRK, 1996). Isto não foi observado neste estudo, onde seis eram fêmeas e quatro eram machos.

A idade de acometimento da dermatite atópica em cães varia de seis meses a sete anos, com $70 \%$ dos cães apresentando os sinais clínicos entre 1 a 3 anos de idade. Há relatos de animais que desenvolvem a atopia antes de 1 ano de idade, isto pode 
refletir parcialmente o ambiente onde os filhotes vivem, a carga alérgena do ambiente, ou quando ambos os genitores são atópicos (MILLER \& KIRK, 1996). Estes dados corroboram com nossos achados, pois todos os animais deste estudo tinham entre 2 e 4 anos de idade.

A hipersensibilidade alimentar foi de $0,36 \%$ em 559 cães com enfermidades dermatológica segundo Hill et al. (2006), enquanto neste estudo foi de $1,56 \%$. A diferença do número de cães em cada um dos estudos pode ter contribuído com os resultados obtidos.

Os distúrbios primários de queratinização ocorreram em 19 cães $(5,45 \%)$, sendo que a seborréia seca foi diagnosticada em 14 casos. A seborréia é uma dermatopatia crônica não contagiosa freqüente em cães e segundo SHANLEY (1991) é a quarta doença mais comum entre esses animais (SHANLEY, 1991), achado semelhante ao descrito nesta pesquisa. Dos 19 casos descritos doze casos eram seborréia secundária e os demais seborréia primária. Os cães que apresentavam seborréia secundária tinham como doença de base a dermatite atópica, a demodicidose e a dermatofitose. Diversos autores descrevem estas doenças como importantes causas de seborréia juntamente com Malasseziose (YURAYART et al., 20110) As doenças de queratinização formam mais observadas em cães da raça Yorkshire (5/19) e em cães sem raça definida (8/19). Somente um caso de seborréia foi diagnosticado nas raças Teckel e Cocker spaniel, consideradas predispostas. Este fato provavelmente ocorreu devido o pequeno número de animais destas raças atendidos.

A maioria das doenças de pele não apresentou predisposição sexual. Foi observada diferença estatística entre machos e fêmeas somente na demodicidose e no complexo foliculite/furunculose/celulite

dentre todas as dermatoses. Na demodicidose as alterações hormonais em fêmeas durante o estro constituem um fator que contribui para o surgimento das lesões (BARRAGRY, 1994), provavelmente colaborando com a maior ocorrência em fêmeas. Porém, não descrição de diferença na incidência sexual no complexo foliculite/furunculose/celulite.

\section{CONCLUSÃO}

Os dados foram coletados nos prontuários do HV-UENP, e não devem ter sofrido influências sazonais por serem referentes a um período de aproximadamente três anos, englobando todas as estações. Os resultados mostraram que a dermatologia na medicina veterinária constitui uma importante área, sendo que o diagnóstico e o manejo dessas enfermidades devem ser considerados de extrema importância aos clínicos de pequenos animais. Salienta-se que são necessários estudos de outras regiões para que seja possível obter um perfil epidemiológico confiável das enfermiades dermatológicas no Brasil.

\section{REFERÊNCIAS}

BALDA, A.L.; LARSSON, C. E.; OTSUKA, M.; GAMBALE W. Estudo retrospectivo de casuística das dermatofitoses em cães e gatos atendidos no Serviço de Dermatologia da Faculdade de Medicina Veterinária e Zootecnia da USP. Acta Scientiae Veterinariae, Porto Alegre, v.32, n.2, p.133-140, 2004.

BARRAGRY, T.B. Demodectic mange (Demodicosis). In: BARRAGRY, T.B. Veterinary drug therapy. Philadelphia: Lea \& Febiger, 1994. cap. , p.385-399.

BELLATO, V.; SARTOR, A.A.; SOUZA, A.P.; RAMOS, B.C. Ectoparasitos em caninos do município de Lages, Santa Catarina, Brasil. Revista Brasileira de Parasitologia 
Veterinária, v.12, n.3, p.95-98, julho/setembro 2003.

CURTIS, C.F. Current trends in the treatment of Sarcoptes, Cheyletiella and Otodectes mite infestations in dogs and cats. Veterinary Dermatology, Oxford, v.15, n.2, p.108-114, março 2004.

DELAYTE, E.H.; OTSUKA, M.; LARSSON, C.E.; CASTRO, R.C.C. Eficácia das lactonas macrocíclicas (ivermectina e moxidectina) na terapia da demodicose canina generalizada. Arquivos Brasileiros de Medicina Veterinária e Zootecnia, Belo Horizonte, v.58, n.1, p.31-38, 2006.

DETHIOUX, F. A dermatite atópica canina, um desafio para o clínico. Focus. Edição Especial, Aimargues, p.01-54, 2006.

EDWARDS, V.M.; DERINGER, J.R.; CALLANTINE, S.D.; DEOBALD, C.F.; BERGER, P.H.; KAPUR, V.; STAUFFACHER, C.V.; $\mathrm{BOHACH}, \mathrm{G} . \mathrm{A}$. Characterization of the canine type $\mathrm{C}$ enterotoxin produced by Staphylococcus intermedius pyoderma isolates. Infection and Immunity, Washington, v. 65, n. 6, p. 2346-2352, junho 1997.

EVANS, J.M.; LANE, D.R.; HENDY, P.G. The profile of small animal practice. Journal Small Animal Practice, London, v.15, n.10, p.595-608, setembro 1974.

FARIAS, M.R.. Dermatite atópica canina: da fisiopatologia ao tratamento. Clínica Veterinária, São Paulo, v.12, n.69, p.48-62, julho/agosto 2007

GHUBASH, R. Parasitic miticidal therapy. Clinical Techniques in Small Practice, Philadelphia, v.21, n.3, p.135-144, agosto 2006.

HIIL, P.B.; LO, A.; EDEN, C.A.N.; HUNTLEY, S.; MOREY, V.; RAMSEY, S.; RICHARDSON, C.; SMITH, D.J.; SUTTON, C.; TAYLOR, M.D.; THORPE, E.; TIDMARSH, R.; WILLIAMS, V. Survey of the prevalence, diagnosis and treatment of dermatological conditions in small animals in general practice. Veterinary Record, Londres, v.158, n.16, p.533-539, abril 2006.
HILLIER, A.; GRIFFIN, C.E. The ACVD task force on canine atopic dermatitis (II): incidence e prevalence. Veterinary e immunology and immunopathology, v.81, n.3-4, p.147-151, setembro 2001

HOLM, B.R.; REST, J.R.; SEEWALD, W. A prospective study of the clinical findings, treatment and histopathology of 44 cases of pyotraumatic dermatitis. Veterinary Dermatology, Oxford, v. 15, n.6, p. 369-376, dezembro 2004.

IHRKE, P.J. Bacterial infections of the skin. In: Diseases of the dog and cat. 2. Philadelphia: Saunders, p.72-79, 1990.

LARSSON, C.E.; LUCAS, R.; GERMANO, P.M.L. Dermatofitoses de case e gatos em São Paulo: estudo de possível influência sazonal. Anais Brasileiros de Dermatologia, São Paulo, v.72, n.2, p.139-142, 1997.

LEITE, C.A.L. As otites de cães e gatos. Parte 1 - Epidemiologia. Revista Cães e Gatos, São Paulo, v.15, p.22-26, 2000.

LEWIS, D.T.; FOIL, C.S.; HOSGOOD, G. Epidemiology and clinical features of dermatophytosis in dogs and cats at Louisiana State University: 1987 - 1990. Veterinary Dermatology, Oxford, v.2, n.2, p.53-58, junho 1991.

LUND, E.M.; ARMSTRONG, P. J.; KIRK, C. A. Health status and population characteristics of dogs and cats examined at private veterinary practices in the United States. Journal American Veterinary Medical Association, Schaumburg, v.214, n.9, p.1336-1341, maio 1999.

MACIEL, A.S.; VIANA, J.A. Dermatofitose em cães e gatos: uma revisão - primeira parte. Clínica Veterinária, São Paulo, v.10, n.56, p.4856, maio/junho 2005.

Ocorrência das dermatopatias em cães e gatos. Revista Brasileira de Ciência Veterinária, Rio de Janeiro, v.7, n.2, p.90, maio/agosto 2000. 
MORIELLO, K.A. Treatment of dermatophytosis in dogs and cats: review of published studies. Veterinary Dermatology, Oxford, v .15, n.2, p.99-107, abril 2004.

MORIELLO, K.A.; DEBOER, D.J. Efficacy of griseofulvina and itraconazole in the treatment of experimental induced dermatophytosis in cats. Journal American Veterinary Medical Association, Schaumburg, v.207, n.10, p.439444, outubro1995.

MUELLER, R.S. Treatment protocols for demodicosis: an evidence-based review. Veterinary Dermatology, Oxford, v.15, n.2, p.75-89, abril, 2004.

NASCENTE, P.S.; XAVIER, M.O.; ROSA, C.S.; SOUZA, L.L.; MEIRELES, M.C.A.; MELLO, J.R.B. Hipersensibilidade alimentar em cães e gatos. Clínica Veterinária, São Paulo, v.11, n.64, p.60-66, setembro/outubro 2006.

NOBRE, M.O.; CASTRO, A.P.; NASCENTE, P.S.; FERREIRO, L.; MEIRELES, M.C.A. Occurrence of Malassezia pachydermatis and others infectious agents as cause external otitis in dogs from Rio Grande do Sul State, Brazil (1996/1997). Brazilian Journal Microbiology, local, v.32, n.3, p. 245-249, agosto/outubro 2001 ,

OLIVEIRA, L.C.; MEDEIROS, C.M.O.; SILVA, I.N.G.; MONTEIRO, A.J.; LEITE, C.A.L.; CARVALHO, C.B.M. Susceptibilidade a antimicrobianos de bactérias isoladas de otite externa em cães. Arquivo Brasileiro de Medicina Veterinária e Zootecnia, Belo Horizonte, v. 57, n. 3, p.405-408, junho 2005.

ROCHETTE, F.; ENGELEN, M.; BOSSCHE, H. Antifungal agents of use in animal health pratical applications. Journal Veterinary Pharmacology Therapy, Utrecht, v.26, n.1, p.31-53, fevereiro 2003.

SCOTT, D.W.; PARADIS, M. A survey of canine and feline skin disorders seen in a university practice: Small Animal Clinic, University of Montreal, Saint-Hyacinthe, Quebec (1987-1988). Canadian Veterinary Journal, Otawa, v.31, n.12, p.830-835, dezembro1990.
SCOTT, D.W.; MILLER, W.H.; GRIFFIN, C.E. Small Animal Dermatology. 6.ed. Philadelphia: W.B. Saunders, 2001, 1528p.

SPARKES, A.H.; GRUFFYLD-JONES, T.J.; SHAW, S.E.; WRIGHT, A.I.; STOKES, C.R. Epidemiological and diagnostic features of canine and feline dermatophytosis in the United Kingdom from 1956 to 1991. Veterinary Record, London, v.133, n.3, p.57-61, julho, 1993.

STREINER, D.L.; NORMAN, G.R. Biostatistics the bare essentials. St. Louis: Mosby -Year Book, 1994, p.260.

TORRES, S.M.F.; MOREIRA, Y.K. Dermatomicoses em cães em Belo Horizonte, Minas Gerais, Brasil. Arquivos Brasileiros de Medicina Veterinária e Zootecnia, Belo Horizonte, v.36, n.10, p.695-701, dezembro 1994.

VON RUEDORFFER, U.; FISCH, R.; PEEL, J.; ROOSJE, P.; GRIOT-WENK, M.; WELLE, M. Flea bite hypersensitivity: new aspects on the involvement of mast cells. Veterinary Journal, Utrecht, v. 165, n.2, p. 149-156, março 2003.

ZIVICNJAK, T. A retrospective evalution of efficacy in therapy for generalized canine demodicosis. Veterinarski Arhiv, Zabreb, local, v.75, n. 4, p.303-310, Mês 2005.

$\begin{array}{llll}\text { YURAYART } & \text { C.; } & \text { CHINDAMPORN, } & \text { A.; } \\ \text { SURADHAT, } & \text { S.; } & \text { TUMMARUK, } & \text { P.; } \\ \text { PRAPASARAKUL, } & \text { N.; } & \text { KAJIWARA, } & \text { S. }\end{array}$ Comparative analysis of the frequency, distribution and population sizes of yeasts associated with canine seborrheic dermatitis and healthy skin. Veterinary Microbiology, Amsterdam, v. 148, n. 2-4, p. 350-362, março de 2011. 